IN PRACTICE

\title{
Social support and sexually transmitted disease related healthcare utilisation in sexually experienced African- American adolescents
}

\author{
L M Lowery, S Chung, J M Ellen
}

Sex Transm Infect 2005;81:63-66. doi: 10.1136/sti.2003.008920

See end of article for authors' affiliations

Correspondence to:

Lisa M Lowery, MD, MPH DeVos Children's HospitalSpectrum Health, Division of Adolescent Medicine, 330 Barclay-Suite 200-Mt 133, Grand Rapids, MI 49503, USA; lisa.lowery@ spectrum.health.com

Accepted for publication 5 April 2004
Objective: To determine whether adolescents' perceived social support predicts future utilisation of sexually transmitted disease (STD) related health care.

Methods: A longitudinal study of African-American adolescents ages 12-18 recruited from a random sample of households in the San Francisco Bay area in which baseline data were collected by telephone and follow up data were collected by telephone or in-home audio computer assisted self interview. At baseline, participants were asked about their sexual behaviours, STD history, and social support. At follow up 14-18 months later, participants were asked whether they, while asymptomatic, had sought STD related medical care within the past year.

Results: Asymptomatic sexually experienced adolescents who talked to their closest friend almost every day were more likely to have had STD related health care in the past year (odds ratio $(O R)=1.38 ; 95 \%$ confidence interval (CI) 1.09, 1.76). Closeness to female and male parents/guardians and participation in extracurricular activities were not associated with utilisation of STD related health care within the past year. After controlling for age and sex, sexually experienced adolescents who talked to or saw their closest friend almost every day were more likely to have had STD related health care within the past year $(\mathrm{OR}=1.35 ; 95 \% \mathrm{Cl}=1.08$ to 1.70$)$.

Conclusions: These findings suggest that friends have an impact on the seeking of confidential healthcare services, such as care for STDs.
$\mathrm{S}$ exually transmitted diseases (STDs) are prevalent among adolescents. Adolescents account for one fourth of the new cases of STDs. ${ }^{1}$ Additionally, racial and ethnic minorities, particularly African-Americans have higher rates of chlamydia and gonorrhoea compared to non-Hispanic whites. ${ }^{2}$ Regular periodic screening for STDs is recommended for early detection and treatment. The US Preventive Services Task Force (USPSTF) strongly recommends the screening of sexually active women 25 years of age and younger. ${ }^{3}$ In a school based health study of urban youth by Aten, $25 \%$ of the adolescents reported no health care in the past 6 months. ${ }^{4}$ Barriers to adolescent access to health care including availability of confidential services, the ability to pay, lack of insurance, transportation, and adolescent friendly environments are reflected in the higher rates of STDs among adolescents. ${ }^{25}$ Understanding facilitators to help navigate around these barriers is a key issue in helping adolescents access the healthcare system.

Adolescents may rely on social support from family members and friends to seek health care including STD related health care. Social support has been associated with positive health practices, STD related health care, and STD related risks. Greater social support is related to less sexual risk. $^{6}$ There is a statistically significant positive correlation between perceived social support and positive health practices such as exercise, nutrition, safety, substance abuse use, and health promotion, which includes yearly check ups. ${ }^{78}$ Parental and peer influences have been shown to impact tobacco, alcohol, and marijuana use, as well as sexual activity.9 Adolescents who resided with their mothers and perceived a supportive family environment were more likely to report having protected sex and frequent communication with their sex partners about sexual risk. ${ }^{10}$ Additionally, those adolescents with a perceived supportive family had more favourable attitudes towards condom use. ${ }^{10}$ Moreover, a low level of family support has been associated with a prolonged time from a female adolescent's recognition of a potential STD problem to the decision to seek care. ${ }^{11}$ Peer groups are highly influential during adolescence and, as adolescents develop, become a source of information and support. Peers also have the capacity to improve adolescent health. ${ }^{12}$ Fortenberry demonstrated that over $80 \%$ of adolescents discussed their STD concerns with someone. ${ }^{11}$ Of those who discussed the problem, 19-48\% of them discussed it with a friend, $31-55 \%$ with their sex partner, and $25-64 \%$ with a family member. ${ }^{11}$

This longitudinal analysis examined the effects of perceived social support on asymptomatic adolescents' seeking of STD related health care. The objective of this analysis was to determine whether adolescents' perceived social support predicts utilisation of STD related health care. We hypothesised that adolescents with greater perceived social support at baseline will be more likely to seek asymptomatic STD related health care 12 months later.

\section{METHODS}

The target sample was sexually experienced AfricanAmerican adolescents aged 12-17 years old who resided in an urban economically disadvantaged neighbourhood in the San Francisco Bay area. The Adolescent Health Study was a longitudinal study, which surveyed adolescents regarding sexual behaviours, STD history, and healthcare use. The study was designed to identify the health seeking behaviours of African-American adolescents. ${ }^{13}$ The study was conducted with the approval of the institutional review board. A baseline telephone interview was conducted between November 1996 and March 1997 on a random sample of households using a list assisted random digit set of telephone 
Table 1 Characteristics of sexually experienced adolescents

\begin{tabular}{|c|c|}
\hline & $\%(n=145)$ \\
\hline Male & 44.0 \\
\hline Ever any STD & 14.5 \\
\hline Sexual intercourse past 3 months & 64.8 \\
\hline Involvement in extracurricular activities & 44.8 \\
\hline \multicolumn{2}{|l|}{ Maternal education } \\
\hline Completed 12 th grade & 53 \\
\hline Some college & 21 \\
\hline \multicolumn{2}{|l|}{ Paternal education } \\
\hline Completed 12 th grade & 51 \\
\hline Some college & 26 \\
\hline Level of perceived social support & Mean (SD) \\
\hline Close to female parent/guardian & $1.3(0.58)^{*}$ \\
\hline Close to male parent/guardian & $1.2(1.10)^{*}$ \\
\hline Contact with closest friend & $1.2(0.75) \dagger$ \\
\hline Extracurricular activities & $0.4(0.50) \ddagger$ \\
\hline \multicolumn{2}{|c|}{$\begin{array}{l}{ }^{*} 1=\text { very close to female/male parent/guardian; } 4=\text { not close at all. } \\
\dagger 1=\text { see or talk to closest friend every day or almost every day; } 6=\text { les } \\
\text { than once a month. }\end{array}$} \\
\hline
\end{tabular}

numbers from three different prefixes in the San Francisco Bay area. ${ }^{13}$ A total of 12858 telephone numbers were sampled. ${ }^{14}$ Only adolescents who were identified by their parent or guardian as being African-American were enrolled in the study. If more than one adolescent lived in the household, each was considered eligible. Verbal parental consent and verbal adolescent assent were obtained. Participation was declined by $13.7 \%$ of the parents or guardians and an additional $9.6 \%$ of the adolescents declined participation or were unavailable. ${ }^{15}$ Of the 285 households contacted and 394 eligible adolescents identified, 302 (77\%) completed the baseline survey.

The follow up interview was conducted 14-18 months after baseline. As part of a larger study to compare responses measuring STD related risk behaviours using telephone survey versus self administered audio computer assisted self interview (A-CASI), eligible participants were randomised to either telephone interview or A-CASI before being recontacted. The participants were told how the interview was going to be conducted as part of the consent/assent process. Written informed consent was obtained from the parents or guardians of participants less than 18 years of age and written assent was obtained from these participants. For those 18 years or older, written consent was obtained from the participants. Participants were interviewed while alone when possible. A parent, guardian, or other adult was reported to be in the same room at any time by less than $10 \%$ of the participants at baseline. At the follow up interview, less than $2 \%$ of participants reported the presence of someone else in the room. ${ }^{15}$ For the purpose of this analysis, only participants who reported being sexually experienced at baseline and completed the follow up (a total of 145) were included.

\section{Measures}

The survey items were designed based on focus groups and pilot tests. At baseline, adolescents were interviewed about their age, sex, school enrolment, grade, sexual experience, STD history, general health care, healthcare utilisation, health insurance, and social support. Adolescents were asked at baseline if they lived with one or both parents/ guardians and their parents'/guardians' level of education. Additional baseline measures included number of siblings, close friends, and relatives. Sexual experience at baseline was measured by asking the participants if they had ever had sex.
"Having sex" was defined as when a boy puts his penis in a girl's vagina.

Measurement of social support was based on a modified Berkman-Syme index. The Berkman-Syme social network index is a validated index, which measures the degree of social integration accounting for number and relative importance of various ties. ${ }^{16}$ The Berkman-Syme index is based on four social connections: (1) marital status, married $v$ unmarried; (2) sociability, frequency and contact with close friends and relatives measured as a subscale with level I-III; (3) religious group affiliation, yes or no; and (4) membership in other social or community organisations, yes or no. ${ }^{16}{ }^{17}$ Higher scores have been associated with decreased morbidity in adults. Marital status was not included because we felt that it was not relevant for our population. Individual aspects of this measure have been associated with reduced risk taking behaviours in adolescents. ${ }^{18-20}$

In our analysis, perceived social support was measured at baseline by level of closeness to female and male guardians, level of interaction with closest friends, and participation in extracurricular activities. Adolescents were asked for both female and male parents/guardians, "How close do you feel to your female/male parent or guardian? By close we mean feeling like you can count on her/him to talk with you about your personal problems and to provide you with emotional support." A 4 point Likert scale, ranging from very close to not close at all, was used to measure parental closeness. The scale was dichotomised into very close and somewhat close to not close at all. Measurement of contact with and closeness to friends was measured by asking the adolescents, "How often do you see or talk with your closest friend?" Contact with friends used a 6 point Likert scale that ranged from every day or almost every day to less than once a month. The scale was dichotomised into every day or almost every day and a few times a week to less than once a month. Extracurricular activity was involvement in any type of community, sports or group sponsored activity. Participation in extracurricular activities was assessed by the question, "In the last 30 days did you participate in an organised activity...yes/no."

At follow up, adolescents were asked about their sexual experience and healthcare utilisation. In order to measure asymptomatic STD related care use, participants were asked "In the past 12 months, have you been checked for a sexually transmitted disease when you did not have any symptoms?"

\section{Analysis}

Participants who had never had sex were excluded from the analysis. Generalised estimating equations (GEE) were used to account for the correlation of repeated measurements within the same household. ${ }^{21}$ Univariate analysis was conducted to determine the unadjusted association between the independent variables of age, sex, number of relatives, number of friends, number of siblings, closeness to female and male guardians, contact with closest friend, involvement in extracurricular activities, healthcare seeking, school enrolment, grade, sexual experience, STD history, general health care, healthcare utilisation, and health insurance status. Variables significant in the univariate analysis were entered into multivariate GEE simultaneously. We controlled for mode of interview, telephone versus A-CASI in all analyses. A p value of $\leqslant 0.05$ was considered statistically significant.

\section{RESULTS}

For responders and non-responders, we compared the independent variables of age, sex, number of relatives, number of friends, number of siblings, closeness to female 
and male guardians, contact with closest friend, involvement in extracurricular activities, healthcare seeking, school enrolment, grade, sexual experience, STD history, general health care, healthcare utilisation, and health insurance status and there was no statistically significant difference between the two groups. Additionally, when comparing the groups based on interview mode there was no statistically significant difference between those who were interviewed via telephone survey and those interviewed using A-CASI. Demographic characteristics of the participants are shown in table 1 . The mean age of the participants was 15.1 years old (SD 1.49). Males comprised $44 \%$ of the sample. Of those that were sexually experienced, $51 \%$ of their fathers/paternal guardians and 53\% of their mothers/maternal guardians had completed high school. In examining STD risk behaviours, $64.8 \%$ of the participants reported having sexual intercourse in the past 3 months and $14.5 \%$ of them reported ever having a STD. Only $38.6 \%$ reported that they used a condom with each sexual act in the past 3 months. Overall, participants reported being close to their parents or guardians (table 1). The mean of closeness to female parent/guardian was 1.3 (SD 0.58). Closeness to male parent/guardian had a mean of 1.2 (SD 1.10). The overall mean for contact with closest friend was 1.2 (SD 0.75). A previous study demonstrated no difference in the level of honesty between the telephone and the A-CASI groups. ${ }^{15}$

School enrolment, grade, sexual experience, STD history, general health care, healthcare utilisation, health insurance status, and number of siblings, close friends and relatives were not statistically significant in the univariate analysis. Whether or not the adolescent lived with the parent or guardian was not statistically significant in the univariate analysis. Univariate and multivariate analyses are shown in table 2. Females were more likely than males to have had STD related health care in the past 12 months (odds ratio $(\mathrm{OR})=1.45 ; 95 \%$ confidence interval $(\mathrm{CI})=1.25$ to 1.69 ). Asymptomatic sexually experienced adolescents who talked to their closest friend almost every day were more likely to have had STD related health care in the past year than those who talked to their closest friend only a few times a week $(\mathrm{OR}=1.38 ; 95 \% \mathrm{CI}=1.09$ to 1.76$)$. Closeness to female and male parents/guardians as well as participation in extracurricular activities were not associated with utilisation of STD related health care within the past year.

The adjusted odd ratios and 95\% confidence intervals are shown in table 2. After controlling for age, sex, and interview mode, sexually experienced adolescents who talked to or saw their closest friend almost every day were more likely to have had STD related health care within the past year $(\mathrm{AOR}=1.35 ; 95 \% \mathrm{CI}=1.08$ to 1.70$)$. Because of the small number who reported closeness to their male parents/ guardians this variable was not included in the final model. The Cronbach's alpha for the social support and social connectedness was 0.85 . Using threshold at 0.6 probability level, the logistic model is about $70 \%$ correctly classified. There was a non-statistically significant association with regard to adolescents reporting closeness to their female guardians, participating in extracurricular activities, and STD related healthcare utilisation. We examined the data for potential interactions between gender and the social support measures of parental/guardian closeness, contact with closest friend, and participation in extracurricular activities and found no interactions.

\section{DISCUSSION}

These findings suggest that friends impact the seeking of confidential healthcare services, such as STD related health care. Asymptomatic sexually experienced adolescents who talked to or saw their closest friend almost every day were more likely to have been evaluated for an STD in the past 12 months. Parental support and participation in extracurricular activities were not significant predictors of STD related health care. Our findings support the association of social support as a facilitator to health care. ${ }^{822} 23$

Social support has been correlated with positive health practices such as yearly health check-ups. ${ }^{8}$ Most adolescents receive some form of social support, including a friend's accompaniment to clinic when seeking STD related care. ${ }^{23}$ While friend support was not statistically significant for either males or females, Fortenberry demonstrated that for females low familial support was associated with a prolonged interval from recognition of a problem and decision to seek care. ${ }^{11}$ Our research demonstrated that closest friend support was associated with seeking STD related health care while familial support and participation in extracurricular activities were not statistically significant predictors of STD related health care. The difference may be related to the fact that Fortenberry's sample had already sought care at the time of the interview or that they used more than one item to measure family and friend support. Additionally, adolescence is a time of transition from more family involvement to more peer centred involvement and support. Beal demonstrated that peers influenced adolescents' health risk behaviours more than (to a greater extent than) parents. ${ }^{9}$ It is possible that adolescents utilise friends more than parents for confidential care as opposed to general health care. MeyerWeitz found that $84 \%$ of adolescents aged 14-20 thought that their good friends would support them seeking STD related care. $^{22}$ Our findings are more consistent with those of Niemiec and Chen. ${ }^{24}$ They examined factors that motivated adolescents to seek care and found that friends rather more than parents were mentioned as an important source in deciding to seek care for STDs. ${ }^{24}$

This analysis has several limitations. Firstly, there was one measure to assess closeness to parents and friends and therefore it may not have completely assessed the level, impact and complexity of social support. To our knowledge no previous research has looked at the Berkman-Syme index in adolescents and without all four of the components. This may affect the validity of the measurement. In addition to having a small effect size, all of the participants were urban African-Americans who lived in an area with a

Table 2 Predictors of seeking STD related health care

\begin{tabular}{lll}
\hline $\mathrm{n}=145$ & Odds ratio $(95 \% \mathrm{Cl})$ & Adjusted odds ratio $(95 \% \mathrm{Cl})^{* *}$ \\
\hline Females & $1.45(1.25 \text { to } 1.69)^{*}$ & \\
>15 years old & $1.17(0.98$ to 1.40$)$ & $1.03(0.89$ to 1.19$)$ \\
Very close to female guardian & $0.94(0.80$ to 1.12$)$ & \\
Very close to male guardian & $0.95(0.78$ to 1.15$)$ & $1.35(1.08 \text { to } 1.70)^{*}$ \\
Contact with closest friend & $1.38(1.09 \text { to } 1.76)^{*}$ & $1.09(0.95$ to 1.27$)$ \\
Extracurricular activities & $1.02(0.87$ to 1.20$)$ & \\
\hline${ }^{*} p$ value $\leqslant 0.05$. & & \\
${ }^{* * A d j u s t e d}$ for age, sex, and interview mode. &
\end{tabular}




\section{Key messages}

- Perceived social support is a facilitator for health care and positive health behaviours

- Peer support, more so than parental support and involvement in extracurricular activities was associated with an asymptomatic adolescent seeking STD related health care. Often thought to have only negative influences on behaviours, peer support was positively associated with STD related healthcare utilisation

- Understanding barriers and facilitators for adolescents seeking confidential care, such as STD related care, will enable improved counselling and the promotion of safer sexual behaviours

high rate of STDs. This may limit overall generalisability. Lastly, the data are self reported and lend themselves to potential recall bias.

Delaying of health care may potentiate high rates of STDs. Multiple factors including social, cognitive, and behavioural impact how adolescents may seek health care. ${ }^{11}$ Social support is a multidimensional concept. While often associated with negative influences, peers have the capability of improving health behaviours. It is important to understand the operational context of social support. Future directions may lead to the adaptation of a Berkman-Syme index that is more specific to adolescents. Furthermore, a greater understanding of the context of the relationships and how they lead to specific healthy behaviours such as health care would be beneficial. Understanding peers as a resource enables health education, promotes positive health practices, and safer health behaviours. Research is needed to assess the depth of social support and its variability across sexes.

\section{ACKNOWLEDGEMENTS}

This work was supported, in part, by grants from the National Center for STD, HIV and TB, Division of HIV Prevention, Centers for Disease Control and Prevention (grant U62-CCU914805-01) and National Institute of Allergy and Infectious Diseases (grant 2R01-A136986). LL is supported by the Faculty Development in Primary Care training grant from the Health Resources and Services Administration, Bureau of Health Professions (grant 5 D14 HP 00118).

\section{CONTRIBUTORS}

LML participated in the whole content of the manuscript, including conception and design, interpretation of the data, and drafting of the manuscript; SC participated in the whole content of the manuscript including analysis and interpretation of the data, critical revision of the manuscript for important intellectual content, and statistical expertise; JE participated in the whole content if the manuscript including conception and design, acquisition of data, analysis and interpretation of the data, drafting of the manuscript, critical review of the manuscript for important intellectual content, obtaining funding, statistical expertise, and supervision.

\section{Authors' affiliations}

L M Lowery, S Chung, J M Ellen, Division of Pediatrics and Adolescent Medicine Department of Pediatrics, Johns Hopkins School of Medicine, Baltimore, MD, USA

There are no relevant financial interests in the manuscript for any of the authors involved.

\section{REFERENCES}

1 Centers for Disease Control and Prevention. Tracking the hidden epidemics: trends in STDs in the United States, 2000. Atlanta: CDC, 2000.

2 Centers for Disease Control and Prevention. Sexually transmitted disease surveillance, 2002. Atlanta, GA: US Department of Health and Human Services, 2003

3 US Preventive Services Task Force. Screening for chlamydial infection: recommendations and rationale. Am J Prev Med 2001;20(3S):90-4.

4 Aten MJ, Siegel DM, Roghmann KJ. Use of health services by urban youth: a school-based survey to assess differences by grade level, gender, and risk behavior. J Adolesc Health 1996;19:258-66.

5 Klein J, Slap G, Elster A, et al. Access to health care for adolescents. A position paper of the Society for Adolescent Medicine. J Adolesc Health 1992;13:162-70.

6 Boyer CB, Tschann JM, Shafer M. Predictors of risk for sexually transmitted disease in ninth grade urban high school students. J Adolesc Res 1999; 14:448-65.

7 Mahat G, Scoloveno MA. Factors influencing health practices of Nepalese adolescent girls. J Pediatr. Health Care 2001;15:251-5.

8 Mahat G, Scoloveno M, Whalen C. Positive health practices of urban minority adolescents. J Sch Nurs 2002;18:163-9.

9 Beal AC, Ausiello J, Perrin JM. Social influences on health-risk behaviors among minority middle school students. J Adolesc Health 2001;28:474-80.

10 Crosby RA, DiClemente RJ, Wingood GM, et al. HIV/STD-protective benefits of living with mothers in perceived supportive families: a study of high-risk African American female teens. Prev Med 2001;33:175-8.

11 Fortenberry JD. Health care seeking behaviors related to sexually transmitted diseases among adolescents. Am.J.Public Health 1997;87:417-20.

12 Brown BB, Dolcini MM, Levethal A. Transformation in peer relationships at adolescence: implications fro health-related behaviour. Cambridge, UK: Cambridge University, 1997

13 Ellen JM, Lane MA, McCright J. Are adolescents being screened for sexually transmitted diseases? A study of low income African American adolescents in San Francisco. Sex Transm Infect 2000;76:94-7.

14 Cunningham S, Tschann J, Gurvey J, et al. Attitudes about sexual disclosure and perceptions of stigma and shame. Sex Transm Infect 2002;78:334-8.

15 Ellen JM, Gurvey JE, Pasch L, et al. A randomized comparison of A-CASI and phone interviews to assess STD/HIV-related risk behaviors in teens. J Adolesc Health 2002;31:26-30.

16 Berkman LF, Syme SL. Social networks, host resistance, and mortality: a nineyear follow-up study of Alameda County residents. Am J Epidemiol 1979; 109: 186-204.

17 Eng PM, Rimm EB, Fitzmaurice G, et al. Social ties and change in social ties in relation to subsequent total and cause-specific mortality and coronary heart disease incidence in men. Am J Epidemiol 2002; 155:700-9.

18 Simantov E, Schoen C, Klein JD. Health-compromising behaviors: why do adolescents smoke or drink?: identifying underlying risk and protective factors. Arch Pediatr Adolesc Med 2000; 154:1025-33.

19 Sabo DF, Miller KE, Farrell MP, et al. High school athletic participation, sexual behavior and adolescent pregnancy: a regional study. J Adolesc Health 1999:25:207-16.

20 Resnick MD, Bearman PS, Blum RW, et al. Protecting adolescents from harm. Findings from the National Longitudinal Study on Adolescent Health. JAMA 1997; 278:823-32.

21 Zeger SL, Liang KY. Longitudinal data analysis for discrete and continuous outcomes. Biometrics 1986;42:121-30.

22 Meyer-Weitz A, Reddy P, Van Den Borne HW, et al. The determinants of health care seeking behaviour of adolescents attending STD clinics in South Africa. J Adolesc 2000;23:741-52.

23 Fortenberry JD, Zimet GD. Received social support for sexually transmitted disease-related care-seeking among adolescents. J Adolesc Health 1999;25: 174-8.

24 Niemiec MA, Chen SP. Seeking clinic care for veneral disease: a study of teenagers. J Sch Health 1978;48:681-6. 